\title{
Embedding implants in undergraduate dental education
}

\author{
R. McAndrew ${ }_{1}^{1}$ J. Ellis, ${ }^{2}$ C. D. Lynch ${ }^{3}$ and M. Thomason ${ }^{4}$
}

- Highlights the barriers and challenges to implant education at undergraduate level.

- Provides insight into how the challenges and barriers to undergraduate teaching of implant based rehabilitation can be overcome.

- Highlights this area of concern to teachers of implant based treatment in the UK.

This article represents the consensus from a meeting of the British Society of Prosthetic Dentistry's Education Group which met to discuss implant dentistry at the undergraduate dental student level. The consensus recognises the need to embed the teaching of implant supported prostheses if such a treatment modality is to be widely practised after graduation. This short article makes some recommendations as well as detailing some challenges and barriers that need to be overcome if implant dentistry is to be successfully embedded in an undergraduate dental curriculum.

Clinical evidence has demonstrated that when restored with implant supported overdentures, edentulous patients have an improved oral health related quality of life and increased satisfaction with their prosthesis in comparison to when conventional dentures are provided. ${ }^{1}$ Conventional dentures are no longer seen by many as the most appropriate first line treatment for the restoration of the edentulous mandible and it is recommended that an implant supported overdenture should be the treatment of choice for the edentulous mandible. ${ }^{2,3}$ Currently the provision of implant supported overdentures is largely limited to secondary care settings and in primary care under private contract. It is believed that there is an unmet need for sufficient numbers of general dental practitioners who are confident and indeed competent in the treatment and maintenance of patients with implant retained prostheses. In order to develop this treatment modality further within the primary dental care environment, and to support patients currently restored with implant retained prostheses,

\footnotetext{
${ }^{1}$ Applied Clinical Research and Public Health, ${ }^{3}$ Tissue Engineering and Reparative Dentistry, School of Dentistry, Cardiff University, Heath Park, Cardiff, CF14 4XY; ${ }^{2,4}$ School of Dental Sciences, University of Newcastle, Dental School, Framlington Place, Newcastle-uponTyne, NE2 4BW

*Correspondence to: Dr Robert McAndrew Email:mcandrew@cf.ac.uk
}

\section{Refereed Paper}

Accepted 9 October 2009

DOI: 10.1038/sj.bdj.2009.1175

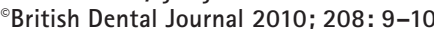

there is a need to provide relevant training for dental practitioners.

This report presents a view from the British Society for the Study of Prosthetic Dentistry's (BSSPD) education group when it met at the $56^{\text {th }}$ Annual Conference in York 2009. The aim of the meeting was to discuss the integration of implant training (in the context of implant supported overdentures) into the undergraduate dental curriculum. The subject was introduced to the group with a number of formal presentations including a review of the relevant undergraduate curriculum requirements, recommendations in relation to the teaching of dental implants at undergraduate level (as published by the General Dental Council), the 2008 Association for Dental Education in Europe (ADEE) workshop on implant dentistry, experiences in delivering undergraduate implant dentistry programmes in the UK and Canada and the published findings from a United Kingdom and Ireland survey.

There is considerable variability of undergraduate implant teaching within the UK, mainland Europe and Northern America. ${ }^{4-8}$ It is known that 13 of the 15 undergraduate dental schools in the UK and Ireland provide teaching and/or training in implantology but with significant variation in the extent, timing, nature and delivery of this training. ${ }^{5}$ At the present time there are no dental schools in the UK who routinely facilitate implant treatment provision by all undergraduates although the majority provide limited exposure to such treatment modalities. Some schools provide opportunities for a small number of students to be directly involved in implant restoration and others plan to introduce such undergraduate clinical experience in the near future. ${ }^{5}$

The delegates were in agreement that suitable training of undergraduates was paramount in order to embed the use of implant supported overdentures as a mainstream treatment strategy for the successful treatment of edentulous patients. The group felt that implant dentistry should be led by teachers within restorative dentistry and must have full horizontal and vertical integration to ensure a good basis for lifelong learning and the development of skills.

Following extensive discussion and reflection, the group felt quite strongly that implant therapy should be taught as a core item within treatment planning for replacing missing teeth and especially where conventional treatment modalities had failed or were inappropriate. It has been shown that implant therapy and treatment is more likely to be offered to patients if it was an integral part of undergraduate training. ${ }^{9}$ It was considered to be important to provide a good grounding in basic implant theory and practice before graduation with competency being assessed in this context. Concern was expressed that currently in the UK much implant training is delivered as short commercially sponsored courses 
that have been organised by the individual implant companies, which provides little or no control on the course content and a risk that marketing strategies and commercialisation may unduly influence what is being delivered.

Curriculum congestion presents a very real barrier to the delivery of additional training at an undergraduate level and the group recognised that in order to effectively deliver education in any implant programme there may need to be increased utilisation of non-traditional teaching methods such as online resource, multi media resource, the Internet, directed and self directed learning. Resource days and modular teaching may also need to be considered when conventional teaching was felt to provide an inappropriate model. The introduction of novel approaches to training opened up the opportunity to develop and share educational resources and in so doing optimise the teaching and learning experience. All agreed that there needed to be a willingness to share experiences in delivering existing teaching programmes.

Clinical experience was felt to be fundamental with respect to education in implant retained prosthodontics and clinical practice experience at undergraduate level within dental schools should be encouraged. However, it is perhaps this area of training which presents the largest challenge in terms of financial resource and ensuring appropriately trained teaching and support staff. Provision of implant retained overdentures was believed to be a very suitable area to be included in undergraduate curricula, and that it should be integrated into the undergraduate programme, rather than being delivered as a 'bolt-on' or extra. It was believed there is considerable merit to be gained by providing experience of restoring patients with implant retained overdentures before progressing to conventional prosthetic treatment and attempting to treat totally edentulous patients with problematic anatomy and unrealistic expectations of what can be achieved. The stability afforded by two osseo-integrated implants could contribute significantly to making many of the more difficult stages in conventional complete denture construction considerably easier eg occlusal registration. This in turn may result in increased confidence among students and an improved learning experience which would allow them to appreciate these clinical procedures more fully rather than worrying over their difficulty.

Other key issues (barriers) which may prevent the development of implant retained prosthodontics teaching and delivery into curricula were highlighted and discussed throughout the day. Issues such as staff training, funding for support staff, patient recruitment, costs of long term maintenance, politics and legislation were just some of the areas explored. It was agreed that these barriers were very often significant and that a concerted effort to overcome them is needed if we are to maximise the benefits of implant retained overdentures for our patients.

In conclusion delegates believed that the skills required for delivering and maintaining implant retained prostheses needs to be fully integrated into the undergraduate dental curriculum if edentulous patients are to benefit routinely from implant supported overdentures. Acquisition of knowledge and clinical skills regarding implant retained restorations was of fundamental importance in undergraduate education if this treatment modality is to be more widely available within primary care. Undergraduates need to graduate with a suitability assessed grounding in implantology from the clinic to the laboratory and skills to expand upon this basic competence. The development of suitable educational programmes needs to link clearly with government health policies and changing population demographics with implant dentistry being no exception. Equally important is the increasing body of research that suggests the positive impact that implant retained prostheses can have on patient satisfaction and oral health related quality of life. ${ }^{1}$ The evidence for this most successful and entirely appropriate treatment modality is clear; our patients, our institutions and indeed our undergraduates should not be denied it.

1. Thomason J M, Heydecke G, Feine J S, Ellis J S. How do patients perceive the benefit of reconstructive dentistry with regard to oral health-related quality of life and patient satisfaction? A systematic review. Clin Oral Implants Res 2007: 18 Suppl 3: 168-188.

2. Thomason J M, Feine J S, Exley C, Moynihan P et al. The York consensus on implant-supported overdentures. Br Dent J 2009; 207: 185-186.

3. Feine J S, Carlsson G S, Awad M A et al. The McGill consensus statement on overdentures. Int $J$ Prosthodont 2002; 15: 413-414.

4. De Bruyn H, Koole S, Mattheos N, Lang N P. A survey on undergraduate implant dentistry education in Europe. Eur J Dent Educ 2009; 13 Suppl 1: 3-9.

5. Addy L D, Lynch C D, Locke M et al. The teaching of implant dentistry in undergraduate dental school in the United Kingdom and Ireland. Br Dent J 2008; 205: 609-614.

6. Afsharzand Z, Lim M V, Rashedi B, Petropoulos V C. Predoctoral implant dentistry curriculum survey: European dental schools. Eur J Dent Educ 2005; 9: 37-45.

7. Petropoulos V C Arbree N S, Tarnow D, Rethman $M$ et al. Teaching implant dentistry in the predoctoral curriculum: a report from the ADEA Implant Workshop's survey of deans. J Dent Educ 2006; 70: 580-588.

8. Seckinger R J, Weintraub A M, Berthold P, Weintraub G S. The status of undergraduate implant education in dental schools outside the United States. Implant Dent 1995; 4: 105-109.

9. Maalhagh-Fard A, Nimmo A, Lepczyk J W, Pink F E. Implant dentistry in predoctoral education: the elective approach. J Prosthodont 2002; 11: 202-207. 